DOI: 10.20472/IAC.2019.048.036

\author{
PADHMA MOODLEY \\ DURBAN UNIVERSITY OF TECHNOLOGY, South Africa
}

\title{
THE ADOPTION OF SOCIAL MEDIA BY ADULT LEARNERS AS AN E-LEARNING PLATFORM
}

\begin{abstract}
:
Recent technological developments have increased the platforms and capacity for learning at HEls. Whilst the adoption of web 2.0 tools by undergraduates continues to be a focus in e-learning discourse, attention should be given to adult learners who are forced to adapt to the spate of technologically innovative educational practices. This paper, explores the experience of adult learners use of social media which is used as an e-learning platform for a course in Research Methodology (RMBA 201). A Facebook page was set up and monitored for the duration of the course which was regularly updated with course slides (in the form of videos) and notifications. Non-probability sampling technique was used in the selection of the sample. Only adult learners' who accessed the prescribed social media designed for the course were eligible to participate in this study. This meant that purposive sampling was used to generate the desired sample. Fifty seven adult learners completed a closed ended questionnaire. The study reveals that although the adult learners were slow to grasp the concept of social media as an e-learning platform, their interest grew exponentially week on week. Furthermore, the test periods saw immense activity from adult learners on the social media, which was indicative of the social media's usefulness as an e-learning platform.
\end{abstract}

\section{Keywords:}

social media; e-learning; adult learners; diffusion of innovation 